\title{
Examining the influence of country-level and health system factors on nursing and physician personnel production
}

\author{
Allison Squires ${ }^{1,2^{*}}$, S. Jennifer Uyei ${ }^{3}$, Hiram Beltrán-Sánchez ${ }^{4}$ and Simon A. Jones ${ }^{5}$
}

\begin{abstract}
Background: A key component to achieving good patient outcomes is having the right type and number of healthcare professionals with the right resources. Lack of investment in infrastructure required for producing and retaining adequate numbers of health professionals is one reason, and contextual factors related to socioeconomic development may further explain the trend. Therefore, this study sought to explore the relationships between country-level contextual factors and healthcare human resource production (defined as worker-to-population ratio) across 184 countries.
\end{abstract}

Methods: This exploratory observational study is grounded in complexity theory as a guiding framework. Variables were selected through a process that attempted to choose macro-level indicators identified by the interdisciplinary literature as known or likely to affect the number of healthcare workers in a country. The combination of these variables attempts to account for the gender- and class-sensitive identities of physicians and nurses. The analysis consisted of 1 year of publicly available data, using the most recently available year for each country where multiple regressions assessed how context may influence health worker production. Missing data were imputed using the ICE technique in STATA and the analyses rerun in $R$ as an additional validity and rigor check.

Results: The models explained $63 \%$ of the nurse/midwife-to-population ratio (pseudo $R^{2}=0.627, p=0.0000$ ) and $73 \%$ of the physician-to-population ratio (pseudo $R^{2}=0.729, p=0.0000$ ). Average years of school in a country's population, emigration rates, beds-per-1000 population, and low-income country statuses were consistently statistically significant predictors of production, with percentage of public and private sector financing of healthcare showing mixed effects.

Conclusions: Our study demonstrates that the strength of political, social, and economic institutions does impact human resources for health production and lays a foundation for studying how macro-level contextual factors influence physician and nurse workforce supply. In particular, the results suggest that public and private investments in the education sector would provide the greatest rate of return to countries. The study offers a foundation from which longitudinal analyses can be conducted and identifies additional data that may help enhance the robustness of the models.

Keywords: Human resources for health, Socioeconomic development, Policy, Global health, Complexity theory, Nurse-to-population ratio, Physician-to-population ratio

\footnotetext{
* Correspondence: aps6@nyu.edu

${ }^{1}$ Rory Meyers College of Nursing, New York University, 433 First Avenue, New York, NY 10010, United States of America

${ }^{2}$ Research on Medical Education Outcomes (ROMEO) Division, School of

Medicine, New York University, 433 First Avenue, New York, NY 10010, United

States of America

Full list of author information is available at the end of the article
} 


\section{Background}

A key component to achieving good patient outcomes is having the right number and type of healthcare professionals with the right resources. Research increasingly demonstrates where and how the healthcare workforce impacts patient outcomes, quality of care, and health inequalities in both primary and acute care settings [1-12]. Political and social determinants of health also contribute to patient outcomes to varying degrees [13].

The production and retention of human resources for health (HRH) at levels that can sustainably achieve good health outcomes seems like it should be the simple case of having enough schools, teachers, and resources to prepare the future healthcare worker to address the healthcare needs of a country's population, followed by appropriate management and governance that creates supportive practice environments. If it were that simple, Latin America and former Soviet Union countries, for example, would not overproduce physicians and under produce nurses [14]. As regional examples of this trend, the country of Georgia has 3.2 nurses and midwives per 1000 population and 4.8 physicians while Colombia has 0.6 nurses per 1000 population and 1.5 physicians per 1000 population. Navarro et al. [15] produced one of the few studies examining this dynamic, but focused their analysis on health outcomes and not health worker production. Countless other examples from around the world suggest that resources and infrastructure are only a small part of the healthcare human resource production equation.

Therefore, this study seeks to explore if country-level contextual factors have an impact on $\mathrm{HRH}$ production and, if so, to what extent. We define country-level contextual factors as those broader institutional structures that affect, directly or indirectly, the healthcare system, population health, and health worker supply and demand. We take the health worker-to-population ratio as a measure of production instead of availability because a measure of health worker availability means the worker is trained and employed as health workers [16]. Since we know health workers may maintain a license or credential even if they are not working in the country (due to domestic un- or underemployment or because they are working abroad) and many countries do not have accurate and updated health worker records (e.g., workers who are alive vs. dead), for the purposes of this paper the measure is used as a marker of production since good quality data about health worker availability is not consistently available. Our focus for this paper is limited to physicians and nurses/midwives since they represent the largest composite group of professional healthcare workers around the world and have the most reliable data sources. We hypothesize that the identified indicators are differentially linked with physician and nurse supply and study these groups separately.
To date, only a few studies have looked at the context of $\mathrm{HRH}$ production at a macro-level [17-19]. Squires and Beltrán-Sánchez [20, 21], for example, conducted two studies that demonstrated a link between educational variables at the State level and the nurse-topopulation ratio in Mexico, with average years of education correlating strongly with the overall ratio $(R=0.69$, $p=0.001$ ) and to the ratio of nurses with specialty training (e.g., operating room, intensive care, obstetrics) $(R=$ $0.54, p=0.020)$. Generally, however, the literature quantifying $\mathrm{HRH}$ production is scarce, comes largely from high-income countries in the form of policy statements, and examines the phenomenon mostly through a supply side lens. At the micro-level, research examines the career intentions of students [22-24], the impact on worker production of teacher shortages [25-27], and education system dynamics that affect supply [28-31]. Research about demand for health workers from epidemiological and demographic forecasts take a broader view but do not consider how a profession itself creates "demand" for individuals to attempt to gain entry into it (via the public image, perceived employment stability, salary, etc.) and other factors that may influence their ability to do so. Thus, exploring production issues just at the micro-level ignores the complex contextual picture that is involved with $\mathrm{HRH}$ production. It does not consider how economic indicators, political factors, and social inequality may influence the production process. This analysis will explore the influence of those factors on $\mathrm{HRH}$ production using physicians and nurses as examples.

\section{Methods}

The design of this observational study draws from multiple disciplines, including the social sciences, health services research, and public health. The theoretical grounding for the study rests in complexity theory combined with a realist perspective. The combined perspectives "understand reality as comprising multiple, nested, open system in which change is generative, context dependent, and time irreversible," (Westhorp, [32], p. 406), further positing that causation occurs through mechanisms that are context sensitive, and capture how micro-level interactions translate into macro-level outcomes $[32,33]$. In the case of healthcare human resource production, this theory provides the structure for understanding how socioeconomic development, political systems, and other national social factors influence HRH production because it is a contextdependent process involving the interactions between multiple systems.

Variable selection drew from a critical review of interdisciplinary literature from healthcare and the social sciences and expert consultation. They represent population characteristics, health system factors, economic variables known to directly affect health systems, a measure 
of political stability, and variables accounting for social inequality in a society. In particular, to attempt to account for the effects of gender-sensitive social inequality, we use the United Nations Development Program's (UNDP) Gender Empowerment Measure (GEM). We selected that variable with the idea that professions that were biased toward one gender or another may have their production affected due to the country's specific dynamic in that area. The combination of these variables attempts to account for the gender- and class-sensitive identities of physicians and nurses. Our variable selection and rationales for choosing them are found in Table 1.

We use nurse/midwife-to-population ratio (NMPR) and the physician-to-population ratio (PPR) as indicators of $\mathrm{HRH}$ production. Combining nurses and midwives into a single aggregated indicator is standard practice for data reporting by the World Health Organization (WHO) because in some countries, nurses are dually trained as midwives or midwives may not have formal training and are categorized as community health workers [34]; therefore, we opted for the aggregated indicator because we felt it was a better representative.
For each indicator, we then conducted a series of negative binomial regression models at the country level while controlling for factors shown in Table 1 and using the country's population size as an offset. The latter step allows us to control for differences in population size across countries. We began the analysis by dividing the variables into five groups as shown in Table 1: population characteristics, health system, political system, economic, and social inequality. Logs were generated for the economic variables "external debt" and "Gross Domestic Purchasing Power Parity (GDPPP)" as a way to reduce variability, a standard practice in economic analyses. For the polity variable, we used the three categories recommended by the Polity IV project for analysis: democracy, anocracy, and autocracy [35]. Figure 1 from the Polity IV project illustrates the 2011 categorizations of global states, which have remained stable since that year.

We began with univariate and bivariate analyses and then proceeded to the multivariate models. Multicollinearity checks based on the variance inflation factor suggested no collinearity issues since all measures were less than ten. The first model included population and health system characteristics, as they represent the variables

Table 1 Variable selection rationale and data sources

\begin{tabular}{|c|c|c|}
\hline Indicator & Link with HRH production and rationale & Data source ${ }^{a}$ \\
\hline \multicolumn{3}{|c|}{ Population characteristics } \\
\hline Schooling & $\begin{array}{l}\text { Average years of school of a country's population. Educational access is a key to producing health } \\
\text { workers. }\end{array}$ & ClA.gov \\
\hline Migrate & Migration rates of a country (in and out). Migration is known to affect health workforce supply. & CIA.gov \\
\hline Urbpop & Urban population percentage. Health workers are known to cluster in urban areas. & ClA.gov \\
\hline \multicolumn{3}{|c|}{ Population health status } \\
\hline $\begin{array}{l}\text { Beds-per-1000 } \\
\text { people }\end{array}$ & Reflects health system capacity for worker employment. & WorldBank.org \\
\hline $\begin{array}{l}\text { Public health } \\
\text { exp }\end{array}$ & Healthcare human resources are the largest expenditure of a health system. & WorldBank.org \\
\hline $\begin{array}{l}\text { Private health } \\
\text { exp }\end{array}$ & & WorldBank.org \\
\hline \multicolumn{3}{|l|}{ Economic } \\
\hline Gini & $\begin{array}{l}\text { The Gini index is considered the best measure of economic inequality in a country. Economic } \\
\text { inequality affects health outcomes because it may affect access to health workers. }\end{array}$ & WorldBank.org \\
\hline $\begin{array}{l}\text { WB Income } \\
\text { Level }\end{array}$ & $\begin{array}{l}\text { The World Bank classifies countries by four income levels: low income, low middle-income, high } \\
\text { middle-income, and high income. It is the best way to control for between country variations in } \\
\text { economic status. }\end{array}$ & WorldBank.org \\
\hline Debtext & External debt affects what a country can spend on healthcare. & CIA.gov \\
\hline GDPPP & $\begin{array}{l}\text { Gross Domestic Purchasing Power Parity is a proxy measure of national income that better accounts } \\
\text { for inequality than GDP per capita. }\end{array}$ & CIA.gov \\
\hline $\begin{array}{l}\text { Political System } \\
\text { [35] }\end{array}$ & $\begin{array}{l}\text { The Polity IV project divides political regimes into three categories: democracy, anocracy, and } \\
\text { autocracy. This allows for categorical analysis of governance variables and reduces variability. }\end{array}$ & $\begin{array}{l}\text { http://www.systemicpeace. } \\
\text { org/polity/polity4.htm }\end{array}$ \\
\hline \multicolumn{3}{|l|}{ Social inequality } \\
\hline GEM & $\begin{array}{l}\text { The Gender Empowerment Measure is how the United Nations Development Program attempts to } \\
\text { measure gender inequality. It is a composite measure of women's relative economic income, } \\
\text { participation in high-paying positions with economic power, and participation in governance. }\end{array}$ & UNDP.org \\
\hline
\end{tabular}



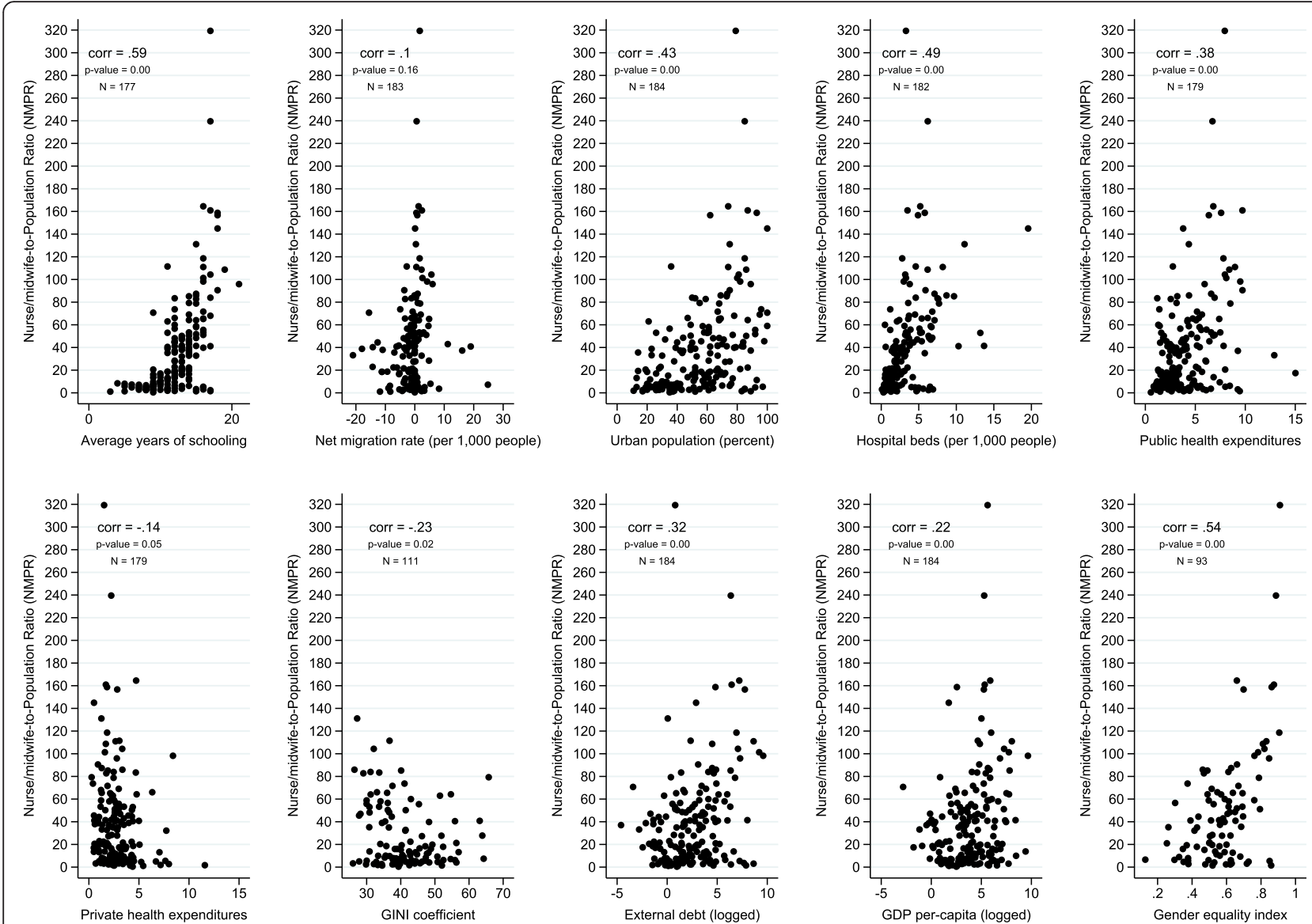

Fig. 1 Associations between the Nurse-Midwife-to-Population Ratio and Selected Development Indicators

closest to the actual healthcare worker. We then tested the impact of political and economic variables on the model in the second iteration. The final model included a social inequality indicator variable, the gender empowerment measure (GEM), which is commonly used in United Nations analyses of gender.

The majority of our independent variables had less than $4 \%$ missing data, but three had substantial data missing (polity 14\%, Gini $40 \%$, and GEM $49 \%$ ). All variables were imputed using chained equation (ICE), a technique available in STATA software, and models were run with and without imputation to check the degree to which the results were influenced by imputation. A pseudo $R^{2}$ result was produced to explain the variation in a model because in the case of this analysis, no direct ways of estimating $R^{2}$ exist. Overall, results were robust to the imputation approach with consistent coefficients in magnitude and direction with and without imputation. All analyses were conducted in STATA, then rerun in $R$ as a validity check. Results from additional checks related to multicollinearity and the imputation approach can be found in the "Additional File 1" online.

\section{Results}

Figures 1 and 2 illustrate the bivariate relationships between the independent and dependent variables for nurses and physicians, respectively. All variables were significantly correlated with the NMPR, except for the net migration rate (Fig. 1). Private sector health expenditure and the Gini coefficient were negatively correlated with the NMPR at $R=-0.15, p=0.04$, and $R=-0.26$, $p=0.03$, respectively. For the PPR, net migration rate was positively and significantly linked but only slightly correlated $(R=0.16, p=0.03)$ while private sector health expenditure was not correlated $(R=-0.07, p=0.29)$ (Fig. 2). Average years of schooling $(R=0.60, p=0.00)$, GEM $(R=0.53, p=0.00)$, and beds-per-1000 population ( $R=0.49, p=0.00$ ) were the top three variables positively correlating with the NMPR. Similarly, the PPR also had average years of schooling $(R=0.71, p=0.00)$ and beds-per-1000 population $(R=0.65, p=0.00)$ in the top three, but urban population percentage $(R=0.60$, $p=0.00)$ beat the GEM's correlation $(R=0.46, p=$ $0.00)$ by 14 points. Gini coefficients had identical negative and significant correlations with the NMPR 

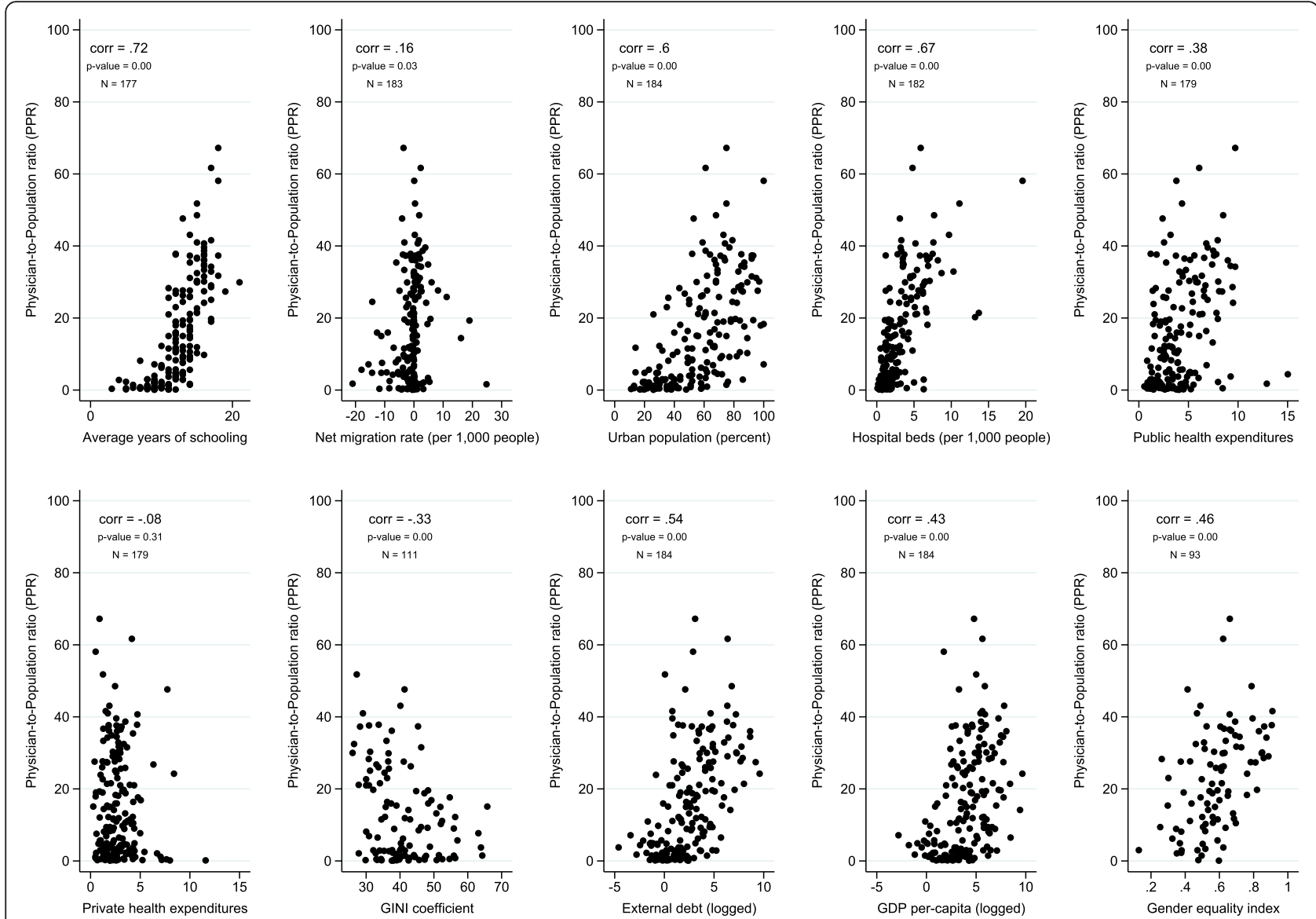

Fig. 2 Associations between the Physician-to-Population Ratio and Selected Development Indicators

$(R=-0.26, p=0.03)$ and PPR $(R=-0.26, p=0.03)$. Further, external debt rates, while both significant, were twice as correlated to the PPR $(R=0.50, p=0.00)$ as the NMPR $(R=0.25, p=0.00)$.

Table 2 illustrates the results from the negative binomial regressions for nurses and physicians. The final model explained $63 \%$ of the NMPR $\left(R^{2}=0.627, p=\right.$ $0.0000)$ and $73 \%$ of the PPR $\left(R^{2}=0.729, p=0.000\right)$ based on the maximum likelihood pseudo $R^{2}$ [36]. Notably, for every additional year spent in school, a country's NMPR increases by $18 \%(p=0.001)$ and PPR increases by $19 \%(p=0.001)$. These results were consistently significant across the models. The beds-per-1000 population were also significant predictors of the total nurse/midwife (11\% increase, $p=0.001)$ and physician (14.5\% increase, $p=0.001$ ) numbers and consistent across the models. Emigrant population rate was also significant for both types of providers, indicating that relative to countries with no migration, those with negative migration flows have significantly higher nursing $(p=0.05)$ and physician $(p=0.001)$ populations. Unsurprisingly, status as a low-income country relative to high income reduces nurse and physician supply by $30 \%$ and was significant for both $(p=0.001)$.

In addition, one variable was only significant for physician supply. Urban population percentage was a significant production predictor across the models for physicians $(p=0.01)$, but not for nurses. Also notable, a country categorized as an "anocracy," relative to democracy, increases its nurse supply numbers by $42 \%$ ( $p=$ 0.050 ) but has no effect on physician supply.

With the exception of low-income country status, none of the other economic variables selected for this study were significant predictors of nurse or physician supply in the fully adjusted models; however, the models suggest some important trends to study further. A one-point increase in GDPPP translates into $5 \%$ more physicians but adds nothing to nursing supply. External debt has an opposite effect for nurses and physicians suggesting a negative effect on the nursing supply, reducing nurses by $4 \%$, but a positive one on physician supply adding $1.4 \%$ more. Economic inequality, as measured by the Gini coefficient, appears to have a minute effect on decreasing physician supply but no effect on nursing numbers. 
Table 2 Coefficient estimates expressed as incidence rate ratios (IRR) from a negative binomial model associating nurse/midwife-topopulation ratio (NMPR) and physician-to-population ratio (PPR) with macro-level variables at the country level

\begin{tabular}{|c|c|c|c|c|c|c|}
\hline \multirow[t]{2}{*}{ Variable } & \multicolumn{3}{|l|}{ NMPR } & \multicolumn{3}{|l|}{ PPR } \\
\hline & Model 1 & Model $2^{a}$ & Model $3^{a}$ & Model 1 & Model $2^{\mathrm{a}}$ & Model $3^{a}$ \\
\hline \multicolumn{7}{|l|}{ Population characteristics } \\
\hline Schooling (years) & $1.216^{* * *}$ & $1.183^{* * *}$ & $1.185^{* * *}$ & $1.221^{* * *}$ & $1.192^{* * *}$ & $1.189^{* * *}$ \\
\hline \multicolumn{7}{|c|}{ Migrate (ref = zero migration) } \\
\hline Emigrant & $1.460^{*}$ & $1.441^{*}$ & $1.458^{*}$ & $2.121^{* * *}$ & $1.848^{* * *}$ & $1.757^{* * *}$ \\
\hline Immigrant & 1.434 & 1.341 & 1.321 & $1.641^{* *}$ & 1.449 & 1.456 \\
\hline Urban population (\%) & 1.003 & 0.999 & 0.999 & $1.019^{* * *}$ & $1.010^{* *}$ & $1.010^{* *}$ \\
\hline \multicolumn{7}{|c|}{ Health system characteristics } \\
\hline Beds-per-1000 people & $1.104^{* * *}$ & $1.108^{* * *}$ & $1.110^{* * *}$ & $1.167^{* * *}$ & $1.151^{* * *}$ & $1.145^{* * *}$ \\
\hline Public health exp & 1.009 & 1.011 & 1.006 & 0.941 & $0.934^{*}$ & 0.953 \\
\hline Private health exp & 0.954 & 0.993 & 0.992 & 1.03 & 1.054 & 1.061 \\
\hline \multicolumn{7}{|c|}{ Political system (ref = democracy) } \\
\hline Autocracy & & 1.045 & 1.042 & & 0.943 & 0.94 \\
\hline Anocracy & & 1.407 & $1.421^{*}$ & & 1.17 & 1.137 \\
\hline \multicolumn{7}{|l|}{ Economy } \\
\hline Gini & & 1 & 1 & & 0.995 & 0.996 \\
\hline \multicolumn{7}{|l|}{ WB income (ref = high) } \\
\hline Middle & & 0.699 & 0.709 & & 0.902 & 0.837 \\
\hline Low & & $0.322^{* * *}$ & $0.333^{* * *}$ & & $0.339^{* * *}$ & $0.303^{* * *}$ \\
\hline External debt & & 0.958 & 0.958 & & 1.009 & 1.014 \\
\hline GDPPPP & & 1.003 & 1 & & 1.052 & 1.058 \\
\hline \multicolumn{7}{|l|}{ Social inequality } \\
\hline GEM & & & 1.243 & & & 0.461 \\
\hline Sample size & 173 & 184 & 184 & 173 & 184 & 184 \\
\hline Maximum likelihood $R^{2}$ & 0.566 & 0.625 & 0.627 & 0.651 & 0.721 & 0.729 \\
\hline
\end{tabular}

WB World Bank, GEM gender empowerment measure, GDPPPP GDP per person ${ }^{* * *} p<0.001 ;{ }^{* *} p<0.01 ;{ }^{*} p<0.05$

${ }^{a}$ Missing data in income was imputed using the ICE method

\section{Discussion}

The strength of the models and their ability to explain 63 to $73 \%$ of the relationship between context and production of the two largest health workforce cadres offers striking new insight into the complex set of dynamics involving health workforce production. For some countries, a grim picture may be present in these results, but the findings do provide some clearer direction for policy initiatives. They also suggest that targeted investments aimed at meeting the sustainable development goals (SDGs) may translate both directly (e.g., quality education, gender equality, good health, and well-being) and indirectly (e.g., no poverty, zero hunger, clean water, and sanitation) into improved health workforce production. More skilled and competent health workers are essential for meeting many of the SDGs.

In consideration of the models, notably comparing pseudo $R^{2}$ for models with different outcomes should be carried out with caution. To partially mitigate this risk, two other methods for estimating pseudo $R^{2}$ were used $[37,38]$ and a comparable difference was still observed. The $10 \%$ difference in variance explained between physicians and nurses in the model, we believe, cannot be explained by existing data because of the amount of cross-national inconsistencies in information systems about healthcare human resources $[39,40]$. Per Riley et al. [40], even if new data were collected, it may not be consistent, of good quality, nor vetted by internationally accountable authority.

In light of the aforementioned data availability and quality issues, an additional variable that may help align the NMPR model to results that are equivalent to the PPR model, along with enhancing its robustness, is the number of nursing and medical schools in each country. Publicly available data about the number of educational institutions would also help to further refine the 
explanation of the strong correlation and significance of the "average years spent in school" of a country's population and the health workforce ratios. Furthermore, Owen and You [41] found that the strength of institutions, like education, helps reduce gender inequality. Equitable access to education contributes to HRH production, primarily by ensuring women's ability to obtain it. Even though the University of Copenhagen maintains a list of the world's medical schools [42], the same data are not available for nursing nor other healthcare professions; neither WHO, the International Council of Nurses, nor comparable organizations have this information publicly available.

An additional education-sensitive, model-enhancing factor specific to nursing personnel would be accounting for the educational variation within the profession. Since nursing education around the world can range from post-secondary through the doctoral level, more precise data about degree composition within the nursing profession at the country level would strengthen the precision of the model, not to mention patient outcome analyses and workforce planning. It would be very helpful for quantifying faculty shortages which will affect production. Data of this type could also provide strategic direction for the best types of degree programs to open in a country in order to facilitate production that can efficiently meet population health needs through universal health coverage and generate optimal outcomes. This model could help provide the evidence for those types of policy changes.

Thus, for enhancing HRH data quality across the professions (and subsequently the quality of future analyses), it would be ideal to capture the total number of schools in a country, faculty and their educational preparation, categories of education (e.g., vocational/practical, bachelors, masters), entry-level education requirements, graduation rates, and employment rate post-graduation. The presence of a licensure exam or similar credentialing process would also be useful. These data would enhance not only labor market analyses but sociological ones and health outcomes analyses.

Despite the challenges of the data and considering other potential explanations for the findings, the dynamics of professional ecology may help explain the differences in the results between physicians and nurses. Medicine has created itself into a socially elite profession around the world. The positions of power and authority physicians hold in many countries ensure that elites and social class mobile individuals will study medicine there, even if they do not stay. Nursing, however, presents an entirely different story. Squires et al. [43] posit that a negative public image of nursing-resulting from a combination of low salaries, poor work environments, female gender association, and, in some places, a lack of career mobility that deters the twenty-first century applicant-creates a cyclic effect that hampers the production of nurses. Social mores around acceptable careers for women and their work schedules (i.e., night shift and its perceived safety for female workers) may further contribute to production issues for nursing personnel. Cross-national data reflecting public opinion of the nursing profession would help to determine the validity of that hypothesis and may help to further explain the ten-point gap in the results of the models between the two professions.

Other aspects of the models allude to the challenges of health system management. Regardless of location, health workers need places to work and bed availability for the population appears to be a proxy indicator of employment opportunity for both physicians and nurses. These results require further study and refinement, however, since nurses may staff primary healthcare systems at greater rates in low-income countries. Furthermore, the total number of listed beds a country reports may not all be in service due to health system financing issues. Future studies that better account for the number of beds-in-use and public primary care clinics in a country may help refine the result.

The significance of the economic and inequality variables in the model suggests that systematic national policies aimed at reducing social, gender, and economic inequality could positively affect health workforce production. It may also explain the finding about the relationship between the NMPR and migration rates since men are more likely to migrate than women [44], women are more likely to follow their migrating husbands than initiate it themselves [45], and low- and middle-income source countries for international nurse migration are dominated by a small number of countries [46]. This may prove especially important for nursing workforce production because of its female gender dominance. Previously, most studies of gender issues in the health professions, besides the aforementioned educational access ones, centered largely on pay disparities between men and women in each occupational group and largely focus on high-income countries [47-51]. Our results indicate that nurse/midwife production may be more sensitive to broader gender inequality issues than physicians. In some ways, this may seem like a "common sense" finding, but research had not previously quantified it.

Finally, when conducting the analyses, we found complexity theory a useful framework for considering variable relationships and selection. Since we aimed to avoid a "kitchen sink" approach to conducting the multivariable regressions, the theory provided direction for how to prioritize variables given our collective, interdisciplinary backgrounds and have the models reflect the 
complex, interconnected systems that are health services delivery and $\mathrm{HRH}$ production.

From a policy perspective, to the best of our knowledge, ours is among the first papers to quantify the significance of how national education policies may impact a country's healthcare worker production. We have known for many decades that education matters for population health, and now, the significance of the relationship is quantified. Our results illustrate the importance of concurrent policy efforts between education and healthcare sectors for stable HRH production and support statements by Frenk et al. [52]. Results from this paper can also be used to help meet international midwifery production goals, as described in the landmark Lancet series published in June of 2014 [53]. The results suggest that policymakers that increase investments in primary and secondary education are likely to see payoffs in increased health worker production.

This analysis is also among the first to highlight how different political regimes and governance issues influence health workforce production. Our results support findings from the social sciences that have shown positive effects of egalitarian regimes on broadly reducing inequality, both economic and gender-based [54]. Finally, the results further help to delineate the nature of political actors who shape healthcare policy, as recommended by van Olmen et al. [55], along with supporting Varghese and Kutty's [56] work on improving governability in public health systems. Findings may also inform the movement toward global health governance by illustrating the impact of States' political systems and governance practices on health workforce production.

In terms of study limitations, known data quality issues in health and development datasets may have affected our results overall due to inconsistencies in reporting across countries and data coordination failures known to affect cross-national datasets [39, 40, 57]. The choice to conceptualize the study on production versus availability was due to the data issues and has its own limitations. For nursing supply data in particular, how countries define nurses and midwives can create fluid interpretations of who qualifies as nursing personnel, and calculations of nursing supply data are not the same across countries $[39,58]$. The beds-per-1000 population data also do not account for beds not in service in the country, which may affect employment opportunities for both physicians and nurses and reflect the financial health of the system. Differentiation between hospitalbased and primary care-based employment was also not possible to obtain through publicly available sources; those data would also add tremendously to the precision of the analysis in future studies. Polity, Gini, and GEM data had substantial data missing and so those variables required more imputation than others in the study, which may have affected the results. Nonetheless, coefficient estimates for the main factors associated with nurses and physicians (e.g., education, migration, and beds-per-1000 population) are of similar magnitude and direction before and after the imputation, suggesting that our substantive results are not driven by the imputation method.

\section{Conclusions}

In conclusion, this study offers a foundation for studying how macro-level contextual factors influence physician and nurse workforce supply. Additional analyses that use this model and add the health worker ratios as independent variables with patient outcomes as the dependent variables will also make for useful contributions to the literature. Future research should also include replicating the study with pharmacy and dental personnel which would be a logical next step to check the stability of the model across professions. When more data becomes publicly available, replication of these cross-country comparative analyses will allow researchers to further refine the methodologies and more precisely account for the impact of potentially confounding factors related to production. Since HRH data quality is improving because its value for policymakers has increased in the last decade, panel data analyses will also become feasible. Event analyses, for example, that can account for major economic and political changes will also allow researchers to study the impact of those events on HRH production over time. Future studies may also want to test other variables in the categories we identified to see if these enhance the model's precision. Hence, for strategic workforce planning initiatives and global health governance, this study makes a useful contribution to the policy dialogue.

\section{Additional file}

Additional file 1: Supplementary results related to multicollinearity and data imputation. (DOC 25 kb)

\section{Abbreviations}

GEM, Gender Empowerment Measure; HRH, human resources for health; ICE, imputation using chained equations; NMPR, nurse/midwife-to-population ratio; PPR, physician-to-population ratio; UNDP, United Nations Development Program; WHO, World Health Organization

\section{Acknowledgements}

The authors would like to thank Karina Schless, BSN, RN, and Lismarys Arjona, $\mathrm{BSN}, \mathrm{RN}$, for their countless hours pulling and cleaning data to help create the dataset for this study.

\section{Funding}

This study was funded by a New York University Global Health Challenge grant and the Pauline Goddard Junior Faculty Fellowship. Funds were used to pay for research assistant services.

Authors' contributions

AS conceived the idea for the study, obtained funding for the project, participated in data analysis, wrote initial paper drafts, and finalized the manuscript for submission. $J U$ contributed to the study design, conducted 
analyses in STATA, and participated in writing the paper. HBS contributed to the study design, conducted analyses in STATA including supplemental regression models, and participated in writing the paper. SJ addressed statistical methods issues in the study, completed the analyses in $R$, and contributed to writing the paper. All authors read and approved the final manuscript.

\section{Authors' information}

AS received her PhD at Yale University in Health Policy, completed a postdoctoral fellowship at the University of Pennsylvania in Health Outcomes Research, and focuses her research on health workforce capacity building strategies and analyses. To date, she has research and programmatic experience in 30 countries, most of them low and middle income. She consults for the World Bank on health labor market analyses with a special emphasis on nursing personnel and is a Fellow with the Migration Policy Institute in Washington, DC, where she works on policy analyses related to international health worker migration. She is currently an associate professor at New York University College of Nursing and a research assistant professor at the School of Medicine.

JU completed her doctorate in Public Health (epidemiology focus) and postdoctoral fellowship (Comparative Effectiveness Research) at New York University. Her research interests come from a decade of work related to HIV prevention in Sub-Saharan Africa and current projects reflect that work. HBS is finishing his third post-doctoral fellowship at the Center for Demography of Health and Aging at the University of Wisconsin after completing a $\mathrm{PhD}$ in demography at the University of Pennsylvania. His two other postdoctoral fellowships were at the University of Southern California and at the Harvard Population Studies Center. His research interests include examining aging and health demographic trends in low- and middle-income countries and developing models to predict health service demand. A native of Mexico, he will assume an assistant professorship at the University of California Los Angeles in the fall of 2015

SJ completed this work when he was a Professor of Epidemiology and Chair of Integrated Care at the University of Surrey in the UK. He is an honorary Senior Fellow at the London School of Economics. He holds a PhD in Math, and prior to his position at Surrey, he held a number of senior-level positions in health and social care, including a secondment as head of analytics to the UK's Center for Workforce Intelligence for Health and Social Care. He also worked on the European Union funded RN4CAST (http://rn4cast.eu/en/) study - a 12-country international comparative nursing workforce study where he was a work package leader for the health outcomes data collection portion of the study. Dr. Jones is now Professor of Population Health at the School of Medicine at New York University.

\section{Competing interests}

The authors declare that they have no competing interests.

\section{Author details}

${ }^{1}$ Rory Meyers College of Nursing, New York University, 433 First Avenue, New York, NY 10010, United States of America. ${ }^{2}$ Research on Medical Education Outcomes (ROMEO) Division, School of Medicine, New York University, 433 First Avenue, New York, NY 10010, United States of America. ${ }^{3}$ Division of Comparative Effectiveness and Decision Science, New York University School of Medicine, 227 East 30th Street, New York, NY 10016, United States of America. ${ }^{4}$ Department of Community Health Sciences, California Center for Population Research, University of California, Los Angeles, 650 Charles E. Young Drive South, Room 41-257 CHS, Los Angeles, CA 53706-1393, United States of America. ${ }^{5}$ Population Health, New York University School of Medicine, 227 East 30th Street, New York, NY 10016, United States of America

\section{Received: 23 February 2015 Accepted: 28 July 2016}

\section{Published online: 15 August 2016}

\section{References}

1. Anand S, Bärnighausen T. Health workers and vaccination coverage in developing countries: an econometric analysis. Lancet. 2007;369:1277-85.

2. Anand S, Bärnighausen T. Human resources and health outcomes: crosscountry. Lancet. 2004;365:1603-9.
3. Ahonkhai A a, Bassett IV, Ferris TG, Freedberg $\mathrm{K}$ a. Improving HIV outcomes in resource-limited countries: the importance of quality indicators. BMC Health Serv Res. 2012;12:427.

4. Ausserhofer D, Zander B, Busse R, Schubert M, De Geest S, Rafferty AM, Ball J, Scott A, Kinnunen J, Heinen M, Strømseng Sjetne I, Moreno-Casbas T, Kózka M, Lindqvist R, Diomidous M, Bruyneel L, Sermeus W, Aiken LH, Schwendimann R. Prevalence, patterns and predictors of nursing care left undone in European hospitals: results from the multicountry cross-sectional RN4CAST study. BMJ Qual Saf. 2014;23:126-35.

5. McHugh MD, Kelly L a, Smith HL, Wu ES, Vanak JM, Aiken LH. Lower mortality in magnet hospitals. Med Care. 2013;51:382-8.

6. Aiken LH, Sermenus W, Van den Heede K, Sloane DM, Busse R, McKee M, Bruyneel L, Rafferty AM, Griffiths P, Moreno-Casbas MT, Tishelman C, Scott A, Brzostek T, Kinnunen J, Schwendimann R, Heinen M, Zikos D, Sjetne IS, Smith HL, Kutney-Lee A. Patient safety, satisfaction, and quality of hospital care: cross sectional surveys of nurses and patients in 12 countries in Europe and the United States. Br Med J. 2012;344:e1717.

7. Carthon JMB, Kutney-Lee A, Jarrín O, Sloane D, Aiken LH. Nurse staffing and postsurgical outcomes in black adults. J Am Geriatr Soc. 2012;60:1078-84.

8. King NB, Harper S, Young ME. Who cares about health inequalities? Cross-country evidence from the World Health Survey. Health Policy Plan. 2012;2012:558-71.

9. Kruk ME, Rockers PC, Mbaruku G, Paczkowski MM, Galea S. Community and health system factors associated with facility delivery in rural Tanzania: a multilevel analysis. Health Policy. 2010;97:209-16.

10. Kruk ME, Wladis A, Mbembati N, Ndao-Brumblay SK, Hsia RY, Galukande M, Luboga S, Matovu A, de Miranda H, Ozgediz D, Quiñones AR, Rockers PC, von Schreeb J, Vaz F, Debas HT, Macfarlane SB. Human resource and funding constraints for essential surgery in district hospitals in Africa: a retrospective cross-sectional survey. PLoS Med. 2010;7:e1000242.

11. McHugh MD, Stimpfel AW. Nurse reported quality of care: a measure of hospital quality. Res Nurs Health. 2012;35:566-75.

12. Ruelas E, Gómez-Dantés O, Leatherman S, Fortune T, Gay-Molina JG. Strengthening the quality agenda in health care in low- and middle-income countries: questions to consider. Int J Qual Health Care. 2012;24:553-7.

13. Lin R-T, Chen Y-M, Chien L-C, Chan C-C. Political and social determinants of life expectancy in less developed countries: a longitudinal study. BMC Public Health. 2012;12:85

14. World Health Organization. Working together for health: the World Health Report 2006. Geneva; 2006

15. Navarro V, Muntaner C, Borrell C, Benach J, Quiroga A, Rodríguez-Sanz M, Vergés N, Pasarín MI. Politics and health outcomes. Lancet. 2006;368:1033-7.

16. O'Brien P, Gostin LO. Health worker shortages and global justice. New York, NY: Milbank Memorial Fund; 2011.

17. Kanchanachitra $C$, Lindelow M, Johnston $T$, Hanvoravongchai $P$, Lorenzo FM, Huong NL, Wilopo SA, dela Rosa JF. Human resources for health in southeast Asia: shortages, distributional challenges, and international trade in health services. Lancet. 2011:377:769-81.

18. Leonardia JA, Prytherch H, Ronquillo K, Nodora RG, Ruppel A. Assessment of factors influencing retention in the Philippine National Rural Physician Deployment Program. BMC Health Serv Res. 2012;12:411.

19. Masselink LE, Lee S-YD. Nurses, Inc:: expansion and commercialization of nursing education in the Philippines. Soc Sci Med. 2010;71:166-72.

20. Squires A, Beltrán-Sánchez H. Predicting nursing human resources: an exploratory study. Policy Polit Nurs Pract. 2009;10:101-9.

21. Squires A, Beltrán-Sánchez H. Exploring the links between macro-level contextual factors and their influence on nursing workforce composition. Policy Polit Nurs Pract. 2011;12:215-23.

22. Ageyi-Baffour P, Rominski S, Nakua E, Gyakobo M, Lori JR. Factors that influence midwifery students in Ghana when deciding where to practice: a discrete choice experiment. BMC Med Educ. 2013;13:64.

23. Burch VC, McKinley D, van Wyk J, Kiguli-Walube S, Cameron D, Cilliers FJ, Longombe AO, Mkony C, Okoromah C, Otieno-Nyunya B, Morahan PS. Career intentions of medical students trained in six sub-Saharan African countries. Educ Health (Abingdon). 2011;24:614.

24. Kaye DK, Mwanika A, Sewankambo N. Influence of the training experience of Makerere University medical and nursing graduates on willingness and competence to work in rural health facilities. Rural Remote Health. 2010;10:1372.

25. Aiken $\mathrm{LH}$, Cheung RB, Olds DM. Education policy initiatives to address the nurse shortage in the United States. Health Aff (Millwood). 2009;28:w646-56.

26. Kowalski K, Kelley BM. What's the ROI for resolving the nursing faculty shortage? Nurs Econ. 2013; 31:70-6. 
27. Smith SR. A recipe for medical schools to produce primary care physicians N Engl J Med. 2011;364:496-7.

28. Daly J, Jill Macleod Clark D, Lancaster J, Orchard C, Polly Bednash G. The Global Alliance for Nursing Education and Scholarship: delivering a vision for nursing education. Int J Nurs Stud. 2008:45:1115-7.

29. Fuchs I, Jotkowitz A. Reversing the brain drain: the role of medical schools. Am J Bioeth. 2012;12:42-3.

30. Garson A. Perspective: leveraging the health care workforce: what do we need and what educational system will get us there? Acad Med. 2011;86:1448-53.

31. Kaufman KA. Findings from the Annual Survey of Schools of Nursing academic year 2010-2011: NLN survey finds unremitting demand for entry into programs while student demographics continue to shift. Nurs Educ Perspect. 2012;33:281-2.

32. Westhorp G. Using complexity-consistent theory for evaluating complex systems. Evaluation. 2012;18:405-20.

33. Durlauf SN. Complexity, economics, and public policy. Polit Philos Econ. 2012;11:45-75.

34. Technical Notes - Global Health Workforce Statistics Database [http://www who.int/hrh/statistics/TechnicalNotes.pdf?ua=1]. Accessed 20 Sept 2012

35. Polity IV Project: Political regime characteristics and transitions, 1800-2012. [http://www.systemicpeace.org/polity/polity4.htm]. Accessed 20 Sept 2012.

36. Long JS, Freese J. Regression models for categorical dependent variables using STATA. 2nd ed. College Station: STATA Press; 2006.

37. McFadden D. Conditional logit analysis of qualitative choice behavior. In: Zarembka P, editor. Front Econom. 1st ed. New York: Academic; 1974. p. $105-42$

38. Cragg JG, Uhler RS. The demand for automobiles. Can Jounal Econ. 1970;3: 386-406.

39. Buchan J, O'May F, Dussault G. Nursing workforce policy and the economic crisis: a global overview. J Nurs Scholarsh. 2013;45(3):298-307.

40. Riley PL, Zuber A, Vindigni SM, Gupta N, Verani A, Sunderland NL, Friedman M, Zurn P, Okoro C, Patrick H, Campbell J. Information systems on human resources for health: a global review. Hum Resour Health. 2012;10:7.

41. Owen AL, You R. Growth, attitudes towards women, and women's welfare Rev Dev Econ. 2009;13:134-50.

42. Directory of World Medical Schools [http://avicenna.ku.dk/]. Accessed 17 July 2014

43. Squires A, Kovner C, Kurth AE. Sustainable nursing human resources systems. In: DeLuca M, Soucat A, editors. Transform glob heal work. 1st ed. New York: New York University College of Nursing; 2013. p. 157-77. Meadows 2008.

44. Tilly C. The impact of the economic crisis on international migration: a review. Work Employ Soc. 2011;25:675-92.

45. World Bank. World Development Report 2012: Gender Equality and Development [Internet]. Washington, DC: World Bank; 2012.

46. Kingma M. Nurse migration and the global health care economy. Policy Polit Nurs Pract. 2008;9:328-33.

47. Chiha YA, Link CR. The shortage of registered nurses and some new estimates of the effects of wages on registered nurses labor supply: a look at the past and a preview of the 21st century. Health Policy. 2003;64:349-75.

48. Lo Sasso AT, Richards MR, Chou C-F, Gerber SE. The $\$ 16,819$ pay gap for newly trained physicians: the unexplained trend of men earning more than women. Health Aff (Millwood). 2011;30:193-201.

49. Morris S, Goudie R, Sutton M, Gravelle H, Elliott R, Hole AR, Ma A, Sibbald B, Skåtun D. Determinants of general practitioners' wages in England. Health Econ. 2011;20:147-60.

50. O'Campo P, Eaton WW, Muntaner C. Labor market experience, work organization, gender inequalities and health status: results from a prospective analysis of US employed women. Soc Sci Med. 2004;58:585-94.

51. Theurl $E$, Winner $H$. The male-female gap in physician earnings: evidence from a public health insurance system. Health Econ. 2011;20:1184-200.

52. Frenk J, Chen L, Bhutta Z a, Cohen J, Crisp N, Evans T, Fineberg H, Garcia P, Ke Y, Kelley P, Kistnasamy B, Meleis A, Naylor D, Pablos-Mendez A, Reddy S, Scrimshaw S, Sepulveda J, Serwadda D, Zurayk H. Health professionals for a new century: transforming education to strengthen health systems in an interdependent world. Lancet. 2010;376:1923-58.

53. Renfrew MJ, Horner CSE, Downe S, McFadden A, Muir N, Prentice T, HoopeBender P. Midwifery: an executive summary for the Lancet's series. Lancet. 2014;384:1-8.

54. Galbraith JK. Inequality and economic and political change: a comparative perspective. Cambridge J Reg Econ Soc. 2010;4:13-27.
55. van Olmen J, Marchal B, Van Damme W, Kegels G, Hill PS. Health systems frameworks in their political context: framing divergent agendas. BMC Public Health. 2012;12:774.

56. Varghese J, Kutty VR. Governability framework for the evaluation and implementation of complex public health functions. Eval Rev. 2012;36:303-19.

57. Schedler a. The measurer's dilemma: coordination failures in cross-national political data collection. Comp Polit Stud. 2011;45:237-66.

58. OECD. Health at a Glance 2011: OECD Indicators, OECD Publishing: Paris. 2011. http://dx.doi.org/10.1787/health_glance-2011-en.

\section{Submit your next manuscript to BioMed Central and we will help you at every step:}

- We accept pre-submission inquiries

- Our selector tool helps you to find the most relevant journal

- We provide round the clock customer support

- Convenient online submission

- Thorough peer review

- Inclusion in PubMed and all major indexing services

- Maximum visibility for your research

Submit your manuscript at www.biomedcentral.com/submit
Biomed Central 